\title{
Hypertension management algorithm for type 2 diabetic patients applied in primary care
}

\author{
Luciana V Viana*', Cristiane B Leitão, Maria F Grillo, Ennio P C C Rocha, Juliana K Brenner, Rogerio Friedman \\ and Jorge L Gross
}

\begin{abstract}
Background: Hypertension frequently coexists with type 2 diabetes (DM), and increases the risk of cardiovascular outcomes. The aim of the study was to obtain/maintain blood pressure (BP) goals (ADA/JNC 7) according to a stepwise algorithm using the medication supplied by the Brazilian government.

Methods: A one-year, single-arm interventional study conducted with type 2 diabetes patients. Intervention consisted of intensification of lifestyle changes and sequential prescription of drugs: diuretic; ACE inhibitors; $\beta$-adrenergic blocking agent and calcium channel blocking agent if $\mathrm{BP}>130 / 80 \mathrm{mmHg}$.

Results: Seventy-eight patients completed the trial. During intervention, the number of antihypertensive tablets rose $(3.6 \pm 3.5$ vs. $5.9 \pm 3.5$ pills/patient; $p<0.001)$, as the number of antihypertensive classes increased ( $1.8 \pm 1.0$ vs. $2.70 \pm 1.2 ; \mathrm{p}<0.01)$ and the overall drop of BP was $11 \mathrm{mmHg}$ for SBP $(145.0 \pm 22.8$ vs. $133.7 \pm 20.9 \mathrm{mmHg}$; $p<0.01)$ and $5 \mathrm{mmHg}$ for DBP $(78.7 \pm 11.5 \mathrm{vs} .73 .7 \pm 10.5 \mathrm{mmHg} ; \mathrm{p}=0.001)$. Although the number of patients with BP in target almost doubled [14 (18.7\%) vs. 30 (38.5\%) $p=0.008$ ], less than $40 \%$ of the patients achieved the proposed goals.
\end{abstract}

Conclusions: A BP algorithm applied to type 2 diabetic and hypertensive patients is able to lower BP, however more than half of the patients did not achieve the ADA/JNC 7 targets demonstrating the complexity of BP control in this population.

Trial registration: ClinicalTrials.gov: NCT06260

Keywords: Type 2 diabetes, Hypertension, JNC 7, ADA guidelines, 'Real life'

\section{Introduction}

Type 2 diabetes and hypertension frequently coexist, and patients with this combination are at a higher risk for cardiovascular events [1]. United Kingdom Prospective Diabetes Study (UKPDS) concluded that tight blood pressure (BP) control in patients with type 2 diabetes and hypertension is able to reduce micro and macrovascular diabetic complications [2]. However, strict BP control in this population, as advised by The Seventh Report of the Joint National Committee on Prevention, Detection, Evaluation and Treatment of High Blood Pressure (JNC 7) and American Diabetes Association (ADA), with a target

\footnotetext{
*Correspondence: vercoza@yahoo.com

Endocrine Division and Primary Care Unit of Hospital de Clinicas de Porto Alegre and Federal University of Rio Grande do Sul, Porto Alegre 90035-003, RS, Brazil
}

\section{Biomed Central}

(c) 2013 Viana et al.; licensee BioMed Central Ltd. This is an Open Access article distributed under the terms of the Creative Commons Attribution License (http://creativecommons.org/licenses/by/2.0), which permits unrestricted use, distribution, and reproduction in any medium, provided the original work is properly cited.
BP lower than $130 / 80 \mathrm{mmHg}$ is difficult to obtain, therefore multiple medications are often required [3-5].

In Brazil, hypertension was present in $81 \%$ of the patients with diabetes participating in the HiperDia System - a program developed to provide antihypertensive and antidiabetic medication in primary care units throughout the country [6]. The aim of this study was to analyze if it is possible to obtain and maintain BP goals (ADA and JNC 7) with an aggressive BP lowering strategy, according to a stepwise algorithm for BP using the medication supplied by the Brazilian government (HiperDia System).

\section{Patients and methods}

Consecutive adult patients (greater than 18 years of age) with type 2 diabetes, who were regularly attending a primary care unit (at least 2 consultation in the last during the 6 -month period before the screening visit), were 
invited to participate in the study. Exclusion criteria were: history of active infection (eg. osteomyelitis, pulmonary tuberculosis, AIDS), chronic corticosteroids use, unstable angina or myocardial infarction in the last 3 months, advanced renal disease - defined as dialysis procedures, severe heart failure (classes 3 and 4), cirrhosis, alcohol or illicit drug use, dementia or difficult to full understand the studies procedures, current pregnancy or lactation, current cancer or any disease that might affect survival in the next 5 years.

At baseline, patients underwent an evaluation consisting of history and physical examination. Patients were considered as smokers or non-smokers. Ethnic definition was self-classified as white or non-white. Previous medical history was evaluated clinically. Cerebrovascular disease was established in the presence of a history of stroke and/or compatible findings (sequelae). The diagnosis of heart disease was based on a previous history of myocardial infarction, angina or heart failure and when available myocardial scintigraphy and coronary angiography. Body mass index (BMI) was calculated [weight $(\mathrm{kg}) /$ height $^{2}(\mathrm{~m})$ ].

Blood pressure (BP) was measured twice at each visit in the sitting position after 10 minutes rest with OMRON Automatic Blood Pressure Monitor HEM- 720. Hypertension was defined as blood pressure levels $\geq 140 / 90 \mathrm{mmHg}$ or use of anti-hypertensive drugs at screening visit. The protocol was approved by the Ethics Committee of Hospital de Clínicas de Porto Alegre and all patients provided written informed consent. This protocol was registered in Clinical Trials (ID 06260).

\section{Study design and interventions}

This one-year, open-label, non-controlled, single-arm interventional study was conducted at a primary care unit located off-campus but in association with Hospital de Clínicas de Porto Alegre, a university hospital, in the metropolitan area of the city of Porto Alegre, Brazil. This unit is responsible for health care of approximately 40.000 individuals. Patients attending the primary care unit with diabetes and hypertension were invited to join the study.

The study comprised 3 stages: a run-in (3 months), drug intervention period (6 months) and stabilization period (2-3 months) and was conducted by an endocrinologist (LVV) and a generalist nurse (MFG). During the run-in period, patients were advised to maintain a healthy diet, to exercise and to take all the medications prescribed by their primary care physicians. Patients visited the primary care unit monthly and received orientation about diet, exercise and adherence to medication already in use. During the intervention period, participants visited the center at monthly intervals to check weight, BP, and glucose. The goal was to obtain systolic and diastolic $\mathrm{BP} \leq 130 / 80 \mathrm{mmHg}$. If the mean systolic or diastolic BP values were higher than 130/80 mmHg, medications were administered in the following sequence: diuretic (hydrochlorothiazide); angiotensin converting enzyme (ACE) inhibitors (captopril or enalapril); $\beta$-adrenergic blocking agent (propranolol) and calcium channel blocking agent (amlopidine). These drugs are provided by the Brazilian public health care system. Medications were available at the primary care unit and patient was able to take it just after the consultation. The patients requiring more than four antihypertensive medications used hydralazine and/or clonidine (not available in the primary care unit). Medication was started with the lowest dose recommended by the manufacturer, and increased in increments until the maximum tolerated dose at monthly intervals guided by BP measurements. Another class of antihypertensive drugs was added after the maximum tolerated dose was reached. During the study period, patients received standard medical care in the primary care unit for intercurrences or other concomitant illness.

\section{Endpoints}

Study endpoints were the change in systolic and diastolic $\mathrm{BP}$ after the intervention as well as the proportion of patients reaching and maintaining a BP $\leq 130 / 80 \mathrm{mmHg}$ during the one-year study period.

\section{Laboratory methods}

Fasting plasma glucose was measured by the glucose oxidase ultraviolet (UV) enzymatic method. Total cholesterol, HDL and triglycerides were measured by enzymatic methods. Low-density lipoprotein cholesterol (LDL) was calculated using the Friedewald equation. Serum creatinine was measured by a kinetic alkaline picrate method (Jaffe reaction) and converted to the standardized Jaffe Roche (CREA), traceable method, by linear regression equation (traceable Jaffe creatinine $=-0.236+1.061 \times$ uncompensated Jaffe creatinine). Urinary albumin was measured in duplicate by immunoturbidimetric method (Microalb; Ames-Bayer, Tarrytown NY). Microalbuminuria was defined by a random spot urine sample higher than $17 \mathrm{mg} / \mathrm{l}[7,8]$. All chemistry parameters were analyzed in a Modular P (Roche ${ }^{\odot}$ (Basel, Switzerland). The HbA1c test measurements (\%) were performed by HPLC.

\section{Statistical analysis}

Results are expressed as mean \pm SD, median (P25-P75) or number of cases with the characteristic (\%). Comparisons were performed by Student's t test, Mann-Whitney $\mathrm{U}$ test or Chi-square test, as appropriate. Paired t-test was used to compare BP variation before and after intervention. $\mathrm{P}$ values $<0.05$ (two-sided) were considered to be statistically significant. SPSS 18.0 - Professional Statistics $^{\mathrm{TM}}$ (SPSS Inc., Chicago, IL, USA) was used. 


\section{Results}

Baseline characteristics

The original cohort comprised 116 diabetic patients of which 107 (92\%) were diagnosed with hypertension. Mean hypertension duration was $10.7 \pm 10.4$ years. The baseline characteristics of the hypertensive patients are shown in Table 1. Most patients were white (82.2\%), 9 (8.4\%) patients were smokers, and the mean BMI was $30.2 \pm 5.9 \mathrm{~kg} / \mathrm{m}^{2}$. At enrollment, diabetes treatment was diet alone in 11 patients, one oral agent in 46, two oral agents in 42, and three medications in 8; insulin was used in 23 (4 patients on insulin alone). Forty-four percent of the patients were on statins and mean LDL was $100.6 \pm 28.4 \mathrm{mg} / \mathrm{dl}$. Twenty-one patients $(19.2 \%)$ had a previous cardiovascular event (stroke $\mathrm{n}=4$; ischemic heart disease $\mathrm{n}=17$; heart failure $\mathrm{n}=3$; lower limb amputation $\mathrm{n}=1$ ) and 25 patients $(23.4 \%)$ were microalbuminuric. Mean systolic BP (SBP) and diastolic BP (DBP) were $145.3 \pm 21.6 \mathrm{mmHg}$ and $79.0 \pm 11.4 \mathrm{mmHg}$, respectively, and BP lower than $130 / 80 \mathrm{mmHg}$ was observed in $16(15 \%)$ patients at the first visit. Hypertension medication previously prescribed by a primary care physician was as follows: no medication in 11 (10.3\%) patients; one agent in $28(26.2 \%)$; two agents in 46 (43\%); three agents in $16(15 \%)$ and four agents in 6 (5.5\%) (69 patients on diuretics, 76 on ACE inhibitor, 36 on beta-blocker agent and 15 patients were using calcium channel blocking agents).

\section{Follow-up results}

Of the 107 hypertensive patients that agreed to participate in the study, 29 (27\%) were lost to follow-up and were not included in the final analysis [withdrawal of consent form ( $\mathrm{n}=3)$, lost to follow-up $(\mathrm{n}=19)$, death $(\mathrm{n}=2)$, stroke with important physical limitation $(\mathrm{n}=1)$, and cancer $(n=4)]$. Therefore, the results of the 78 patients $(73 \%)$ that completed the trial are presented below. There was no difference between missing patients and those who completed the follow-up regarding age, sex, duration of hypertension and diabetes, and BP levels.

Changes in blood pressure are shown in Figure 1. From baseline to the end of the run-in period, there was a significant reduction in both systolic (145.0 \pm 22.8 vs. $138.8 \pm 21.2 \mathrm{mmHg} ; \mathrm{p}=0.002)$ and diastolic BP $(79.4 \pm$ 11.5 vs. $76.5 \pm 10.9 ; \mathrm{p}=0.026$ ), yet no increase in the number of pills taken in this first part of the study was observed $(3.4 \pm 3.5$ vs. $3.8 \pm 3.5 ; \mathrm{p}=0.137)$. In the intervention period, the number of antihypertensive tablets increased ( $3.6 \pm 3.5$ vs. $5.9 \pm 3.5$ pills/patient; $\mathrm{p}<0.001)$, as the number of antihypertensive classes increased $(1.8 \pm 1.0$ vs. $2.70 \pm 1.2 ; \mathrm{p}<0.01)$. During this period, a further decline in SBP and DBP was observed and the overall drop of BP was $11 \mathrm{~mm} \mathrm{Hg}$ for SBP (145.0 \pm 22.8 vs. $133.7 \pm 20.9 \mathrm{mmHg} ; \mathrm{p}<0.01)$ and $5 \mathrm{mmHg}$ for
Table 1 Baseline clinical and laboratory characteristics of 107 hypertensive type 2 diabetic patients

\begin{tabular}{|c|c|}
\hline Baseline & \\
\hline $\bar{N}$ & 107 \\
\hline Age (years) & $62.6 \pm 11.2$ \\
\hline White ethnicity - n (\%) & $88(82.2 \%)$ \\
\hline Female sex- n (\%) & $69(64.5 \%)$ \\
\hline Diabetes duration (years) & $8.3 \pm 9.2$ \\
\hline Primary care unit attendance (years) & $2.3 \pm 2.7$ \\
\hline Previous cardiovascular event - $\mathrm{n}(\%)$ & $21(19.2 \%)$ \\
\hline Current Smoking - n (\%) & $9(8.4 \%)$ \\
\hline $\mathrm{SBP}(\mathrm{mmHg})$ & $145.3 \pm 21.6$ \\
\hline $\mathrm{DBP}(\mathrm{mmHg})$ & $79.0 \pm 11.4$ \\
\hline $\mathrm{BMI}\left(\mathrm{kg} / \mathrm{m}^{2}\right)$ & $30.2 \pm 5.9$ \\
\hline Using statin - n (\%) & $47(44 \%)$ \\
\hline Using aspirin- $\mathrm{n}(\%)$ & $66(61.8 \%)$ \\
\hline Microalbuminuria- n (\%) & $25(23.4 \%)$ \\
\hline \multicolumn{2}{|l|}{ Diabetes Treatment - n (\%) } \\
\hline Diet only & $11(10.3 \%)$ \\
\hline One agent & $46(43 \%)$ \\
\hline Two agents & $42(39.2)$ \\
\hline Three agents & $8(7.5 \%)$ \\
\hline Insulin use & $23(21.5 \%)$ \\
\hline \multicolumn{2}{|l|}{ Hypertension Treatment } \\
\hline No drugs & $11(10.3 \%)$ \\
\hline One agent & $28(26.2 \%)$ \\
\hline Two agents & $46(43 \%)$ \\
\hline Three agents & $16(15 \%)$ \\
\hline Four agents & $6(5.5 \%)$ \\
\hline Diuretic & 69 \\
\hline ACE inhibitor & 76 \\
\hline B-blocker & 36 \\
\hline Calcium channel blocking & 15 \\
\hline Total cholesterol (mg/dl) & $179.9 \pm 39.7$ \\
\hline HDL cholesterol (mg/dl) & $48.0 \pm 11.3$ \\
\hline Triglycerides (mg/dl) & $152(107.3-368.7)$ \\
\hline LDL cholesterol (mg/dl) & $100.6 \pm 28.4$ \\
\hline $\mathrm{HbA1c}(\%)$ & $7.3 \pm 1.6$ \\
\hline
\end{tabular}

Data are mean $\pm S D$, number of patients with the characteristic (\%).

DBP $(78.7 \pm 11.5$ vs. $73.7 \pm 10.5 \mathrm{mmHg} ; \mathrm{p}=0.001)$; the number of patients with BP values lower than $130 / 80$ $\mathrm{mmHg}$ almost doubled [14 (18.7\%) vs. 30 (38.5\%) $\mathrm{p}=$ 0.008] from the first visit to the end of the study. During the stabilization period there was neither a decline in BP nor an increase in medication taken.

In order to identify baseline characteristics associated with better responses to the intervention, patients were 

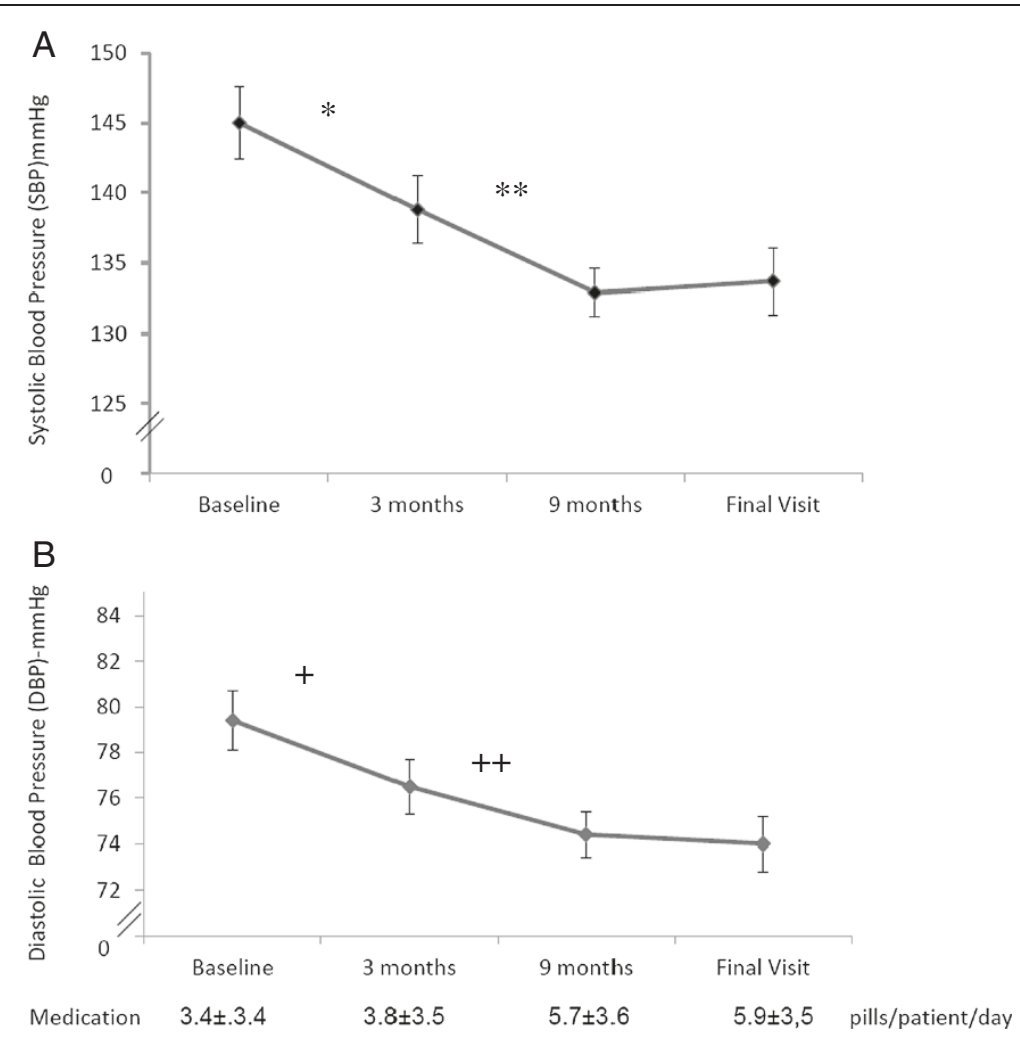

Figure 1 Blood Pressure decrease and Medication Tablets increase throughout the study: Panel A - Systolic Blood Pressure (mean \pm SE); *Run-In: Systolic BP: $145.0 \pm 22.8$ vs. $138.8 \pm 21.2 \mathrm{mmHg} ; \mathrm{p}=0.002$; ** Intervention Systolic BP: $138.5 \pm 21.21$ to $132.6 \pm 14.8 \mathrm{mmHg}$; P = 0.046; Panel B - Diastolic Blood Pressure (mean \pm SE). +Run-In: Diastolic BP: $79.4 \pm 11.5$ vs. $76.5 \pm$ 10.9; $p=0.026$; ++ Intervention Diastolic BP: $76.4 \pm 11.05$ to $74.4 \pm 8.6 ; \mathrm{P}<0.01$

stratified based on BP values at the end of the study. No differences regarding age, gender, and hypertension duration were seen between patients reaching BP goals, with the exception of a higher SBP at baseline in those with BP higher than $130 \mathrm{mmHg}$ at the end of the study.

\section{Conclusion}

In this cohort of type 2 diabetic and hypertensive patients, mean initial BP was $145 / 79 \mathrm{mmHg}$ and only $15 \%$ of patients had ADA and JNC 7 target BP levels. During this one-year study, the number of patients who achieved the goal increased to $39 \%$, with a mean drop of $11 \mathrm{mmHg}$ in the SBP and $5 \mathrm{mmHg}$ in DBP. The end-of-study BP was $\sim 134 / 74 \mathrm{mmHg}$ due to an important increase in the number of pills taken by these patients. It is worth noting that less than half the study participants ended the follow-up with a BP $<130 / 80 \mathrm{mmHg}$.

Our baseline data is in agreement with previous results from a cross-sectional study conducted in Porto Alegre, Brazil, where $83 \%$ of the treated patients had BP levels higher than ADA goals [5]. A survey of NCHS examined hypertension management in diabetic patients and demonstrated that $66 \%$ of the diabetic patients visiting outpatient clinics had BP higher than the goals, with a mean of 139/78 mmHg. Interestingly, $71 \%$ of these patients were using antihypertensive agents, with nearly half involving prescription of 2 or more medications [9].

Therapeutic inertia is an important factor contributing to persistent elevated BP in these patients. In a crosssectional study, researchers from Colorado found that more than $60 \%$ of type 2 diabetic patients did not achieve blood pressure goals, and actions to lower BP were taken in only $35 \%$ of the cases [10]. In our study, an aggressive BP lowering strategy, consisting of monthly evaluations and forced medication titration, doubled the number of patients with BP below the target. Two other strategies were tested in recently published trials to control BP in diabetic populations $[11,12]$. The addition of a pharmacist and a nurse to manage the patients cardiovascular risks in primary care resulted in BP reductions similar to those observed in the present study $[11,12]$.

Another important factor that could contribute to the low number of patients on target is patient's non-adherence to lifestyle modification strategies. The decrease in BP observed in the run-in period probably reflects an improvement in patient's adherence to behavior modification reinforcements (lifestyle intervention) in the first 3 months 
of the study. There was no significant weight loss throughout the study despite orientation about diet and exercise at each appointment. Modifying diabetic patients diet is another important way to reduce BP. DASH diet applied to a diabetic population was able to reduce both systolic BP and diastolic blood pressure $(-13.6 \pm 3.5$ $\mathrm{mmHg} ;-9.5 \pm 2.6 \mathrm{mmHg}$, respectively) [13].

Recently, BP targets in patients with diabetes and hypertension have been debated $[14,15]$ because only one intervention study testing different BP goals was able to lower patients BP levels to ADA and JNC 7 recommendations [16]. In this scenario, a less strict blood pressure control (BP $<140 / 80 \mathrm{mmHg}$ or between $130-135 \mathrm{mmHg}$ ) as suggested by a recent meta-analysis [17] may be considered a more adequate target. Even when analyzed from this perspective (BP $<140 / 80 \mathrm{mmHg}$ ) which matches the new recommendation from ADA 2013 [18], only 31\% of our patients were initially well controlled and after the study intervention this number increased to $54 \%$, leaving $46 \%$ of the patients at a higher risk for diabetic complications.

In conclusion, a BP algorithm applied to type 2 diabetic and hypertensive patients is able to lower BP, however more than half of the patients did not achieve the ADA and JNC 7 targets, demonstrating the complexity of BP control in this population. Revision of antihypertensive treatment strategies, perhaps employing a more aggressive life-style intensification strategy and/or including new classes of agents, is needed in order to guarantee an adequate BP control in patients with type 2 diabetes.

\section{Competing interests}

The authors declare that they have no competing interests.

\section{Authors' contributions}

LW researched data and wrote manuscript. MFG, EPPCR and JKB researched data. CBL, RF and JLG reviewed/edited the manuscript and contributed to discussion. All authors read and approved the final manuscript.

Received: 26 June 2013 Accepted: 7 September 2013

Published: 12 September 2013

\section{References}

1. Mancia G: The association of hypertension and diabetes: prevalence, cardiovascular risk and protection by blood pressure reduction. Acta Diabetol 2005, 42:S17-S25.

2. UK Prospective Diabetes Study Group: Tight blood pressure control and the risk of macrovascular and microvascular complications in type 2 diabetes: UKPDS 38. BMJ 1998, 317:703-713.

3. Chobanian AV, Bakris GL, Black HR, Cushman WC, Green LA, Izzo JL Jr, Jones DW, Materson BJ, Oparil S, Wright JT Jr, Roccella EJ, National Heart, Lung, and Blood Institute Joint National Committee on Prevention, Detection, Evaluation, and Treatment of High Blood Pressure, National High Blood Pressure Education Program Coordinating Committee: The seventh report of the joint committee on prevention, detection, evaluation, and treatment of high blood pressure. JAMA 2003, 289:2560-2572.

4. American Diabetes Association: Standards of medical care in diabetes, 2010. Diabetes Care 2010, 34:S11-S61.

5. Pinto LC, Ricardo ED, Leitão CB, Kramer CK, Zanatta CM, Gross JL, Canani LH: Control inadecuado de la presion arterial en pacientes con diabetes melito tipo 2. Ara Bras Cardiol 2010, 94:633-637.
6. Ferreira CLRA, Ferreira MG: Características epidemiológicas de pacientes diabéticos da rede pública de saúde: análise a partir do sistema HiperDia. Ara Bras Endocrinol Metab 2009, 53:1.

7. Zelmanovitz T, Gross JL, Oliveira JR, Paggi A, Tatsch M, Azevedo MJ: The receiver operating characteristics curve in the evaluation of a random urine specimen as a screening test for diabetic nephropathy. Diabetes Care 1997, 20:516-519.

8. Sociedade Brasileira de Diabetes: Diretrizes da sociedade brasileira de diabetes 2009. 2009.

9. Aparasu RR, Aparasu A: Hypertension management in outpatient visit by diabetic patients. Res Soc Admin Pharm 2008, 4:284-291.

10. Hicks PC, Westfall JM, Van Vorst RF, Bublitz Emsermann C, Dickinson LM, Pace W, Parnes B: Action or inaction? Decision making in patients with diabetes and elevated blood pressure in primary care. Diabetes Care 2006, 29:2580-2585.

11. Simpson SH, Majumdar SR, Tsuyuki RT, Lewanczuk RZ, Spooner R, Johnson $J A$ : Effect of adding pharmacists to primary care teams on blood pressure control in patients with type 2 diabetes: a randomized controlled trial. Diabetes Care 2011, 34:20-6.

12. Ishani A, Greer N, Taylor BC, Kubes L, Cole P, Atwood M, Clothier B, ErcanFang $N$ : Effect of nurse case management compared with usual care on controlling cardiovascular risk factors in patients with diabetes: a randomized controlled trial. Diabetes Care 2011, 34:1689-1694.

13. Azadbakht L, Fard NR, Karimi M, Baghaei MH, Surkan PJ, Rahimi M, Esmaillzadeh A, Willett WC: Effects of the Dietary Approaches to Stop Hypertension (DASH) eating plan on cardiovascular risks among type 2 diabetic patients: a randomized crossover clinical trial. Diabetes Care 2011, 34:55-7.

14. Macia G, Grassi G, Zanchetti A: Antihypertensive treatment and blood pressure in diabetic and nondiabetic patients. Diabetes Care 2011, 34:S304-S307.

15. Grossman E: Blood pressure: the lower, the better. Diabetes Care 2011, $34: 5308-S 312$

16. The ACCORD, Study Group: Effects of intensive blood-pressure control in type 2 diabetes mellitus. N Engl J Med 2010, 362:1575-1582.

17. Bangalore S, Kumar S, Lobach I, Messerli FH: Blood pressure targets in subjects with type 2 diabetes mellitus/impaired fasting glucose: observations from traditional and bayesian random-effects metaanalyses of randomized trials. Circulation 2011, 123:2799-810.

18. American Diabetes Association: Standards of medical care in diabetes, 2013. Diabetes Care 2013, 36:S13-S66.

doi:10.1186/1758-5996-5-52

Cite this article as: Viana et al:: Hypertension management algorithm for type 2 diabetic patients applied in primary care. Diabetology \& Metabolic Syndrome 2013 5:52.

\section{Submit your next manuscript to BioMed Central and take full advantage of:}

- Convenient online submission

- Thorough peer review

- No space constraints or color figure charges

- Immediate publication on acceptance

- Inclusion in PubMed, CAS, Scopus and Google Scholar

- Research which is freely available for redistribution 